\section{Preterm respiratory disease in the modern era: the value of cohort studies}

\author{
Gregory S Montgomery, Stephanie D Davis
}

Since bronchopulmonary dysplasia (BPD) was first described in 1967, the respiratory phenotype of the preterm infant has evolved. ${ }^{1}$ Over the past several decades, the management approach to treating these immature lungs, often in the saccular phase of development, has advanced leading to the survival of preterm infants born as early as 23-24 weeks gestational age. In the postsurfactant era, our understanding of the physiologic and structural pathogenesis of the respiratory system of these very low gestational age infants is poorly understood.

In this issue of Thorax, two Australian research teams delineate phenotypic features of the respiratory system in school age children and adolescents born prematurely. Simpson et $a l^{2}$ present a casecontrol study evaluating a broad spectrum of lung function and imaging measures in former preterm ( $\leq 32$ weeks gestation) school age (9-11-year-old) children born between 1997 and 2003. Doyle et $a l^{3}$ present a prospective cohort study of lung function measures at school age (8 years) and again in late adolescence (18 years) in former premature children ( $\leq 28$ weeks gestation and/or $<1000 \mathrm{~g}$ birth weight) born between 1991 and 1992. Both preterm populations consisted of children with and without the diagnosis of BPD.

Prior investigators detail lung function impairment in school age, adolescent and adult individuals born prematurely. ${ }^{4} 5$ Unlike the two reports in this issue of Thorax, few prior studies evaluated participants born in the so-called postsurfactant or 'new BPD' era. Other confounding variables in prior studies include inconsistent definitions and application of the BPD diagnosis, as well as lack of uniform lung function reference values that span across all ages. ${ }^{6}$ Both Australian groups defined BPD based on the National Heart Lung

Section of Pediatric Pulmonology, Allergy \& Sleep Medicine, Department of Pediatrics, Indiana University School of Medicine, Riley Hospital for Children at IU Health, Indianapolis, Indiana, USA

Correspondence to Dr Stephanie D Davis, Riley Hospital for Children at IU Health, 705 Riley Hospital Dr. RI 5900, Indianapolis, IN 46202, USA; sddavis3@iu.edu
Blood Institute (NHLBI) consensus guidelines, ${ }^{7}$ and each utilised the Global Lung Initiative reference values ${ }^{8}$ for determining spirometry z-score calculations. Furthermore, large cohort studies are difficult to conduct and delineating the natural history of the respiratory phenotype in this understudied population is integral when defining validated endpoints for future intervention studies.

The most significant finding from both studies is the similar degree of obstructive lung disease in children born prematurely when compared with matched control participants. These findings are characterised by modest reductions in $\mathrm{z}$-score measures of $\mathrm{FEV}_{1}, \mathrm{FEF}_{25-75}$ and $\mathrm{FEV}_{1} /$ FVC ratio, with more significant reduction seen in individuals meeting the diagnosis of BPD based on the NHLBI definition. However, even those without BPD had reductions in airflow, highlighting the often silent airway obstruction that occurs in this preterm population. Furthermore, in the Perth participants, $\mathrm{FEV}_{1}$ z-score values in this school age population were directly associated with both gestational age and birth weight. These findings highlight that the trajectory of lung function impairment in preterm children may be determined prior to discharge from the neonatal intensive care unit. Identifying those infants who will develop the most severe respiratory impairments as well as intervening at the earliest time period remains critical.

Have we made progress through our current management approach in this preterm population? Interestingly, the Melbourne group recently showed that a similar cohort of patients born 5 years after the current group in this issue of Thorax have similar degrees of lung function impairment at 8 years of age. ${ }^{9}$ This strongly suggests that our current therapeutic approach to these preterm infants remains insufficient to meaningfully impact the severity and progression of lung disease later in childhood, despite improvements in overall mortality.

Additional lung function techniques including multiple breath washout (MBW), diffusing capacity of the lung for carbon monoxide and forced oscillation were each associated with some indices of premature chronic lung disease (low birthweight, duration of positive airway pressure and days of oxygen use). However, none of these non-invasive lung function techniques provided significant supplementary physiologic data when compared to routine spirometry. Failure of MBW to clearly identify individuals with premature lung disease is quite striking when compared to more robust findings reported in cystic fibrosis (CF) lung disease. ${ }^{10}$ This discrepancy may be attributable to the physiologic origins of these disease processes. In $\mathrm{CF}$, airway disease occurs in a heterogeneous pattern, but in BPD the lung disease is more homogeneous. This heterogeneous airway disease in CF leads to ventilation inhomogeneity and an elevation in the lung clearance index. Given that MBW and oscillometry are simple tidal breathing techniques, this finding proves disappointing since the young child is often unable to cooperate for spirometry. Difficulty in performing spirometry is escalated in the often developmentally delayed preterm child.

Findings on chest CT scans in the Perth study showed a greater prevalence of structural abnormalities in children with BPD. The anomalies of linear and triangular subpleural opacities on CT were associated with lower gestational age, lower birthweight and duration of respiratory support. However, the true clinical usefulness of CT scan imaging in care of patients with BPD remains unclear and further investigation delineating the significance of the visualised lung pathology on CT scans is warranted. Novel imaging techniques such as hyperpolarised noble gas MRI, which may be used to indirectly calculate alveolar number in children with BPD, have great potential to elucidate the underlying structural disease in the preterm population. ${ }^{1112}$

Longitudinal spirometric data from two time points in the Melbourne cohort highlights that the severity of lung function abnormalities in former preterm school age children are not static, but rather progressive in nature. Deterioration in the z-scores of certain spirometry variables (notably, $\mathrm{FEV}_{1} / \mathrm{FVC}$ and $\mathrm{FEF}_{25-75}$,) between 8 and 18 years of age strongly suggest ongoing pathologic changes to the respiratory system of former premature infants. However, FVC continues to increase while these spirometric measures of airway obstruction diminish. The authors state that dysanaptic pulmonary development (slower growth of the airway compared to lung parenchyma) may be a possible explanation for this observation. Dysanapsis has been 
observed in healthy adolescents ${ }^{13}$ and been implicated in complications of other chronic lung diseases such as CF. ${ }^{14}$ The discrepancy between FVC and indices of airway obstruction over time underscores our need for better understanding of normal dynamic lung growth as well as in pathological conditions such as preterm lung disease. An additional finding within the Melbourne cohort emphasises the additive deleterious effects of smoking in survivors of premature lung disease. The significant $\mathrm{FEV}_{1}$ decline between 8 and 18 years of age for preterm smokers highlights the need for continued aggressive smoking cessation efforts. Cohort studies such as the two highlighted in this issue of Thorax are integral to our understanding of growth within the respiratory system.

The distinct pathological characteristics of postsurfactant 'new' BPD have been well described, ${ }^{15}$ but the avenues for effective clinical intervention remain elusive. These two studies exhibit an increased risk for preterm children to develop significant lung pathology into adulthood. Delineating the underlying pathophysiology of the preterm respiratory phenotype remains paramount. We need to define the optimal time for clinical intervention with a goal of aggressive reduction in lifelong respiratory morbidity. Identification of sensitive biomarkers that predict respiratory impairment may allow for effective intervention early in the course of the preterm lung disease process. Recent prospective evaluations note findings as early as 7 days of age that may be associated with not only subsequent development of BPD, but also with complicating morbidities such as pulmonary hypertension. ${ }^{1617}$ The call for primary prevention of BPD is not new. The NHLBI workshop for the prevention of chronic lung diseases unambiguously states '...not all infants born extremely preterm develop BPD; thus we propose that BPD can be prevented, not just ameliorated, in most patients'. ${ }^{18}$
Given the significant respiratory morbidity that often presents without overt clinical symptoms, these preterm children should be followed closely postneonatal intensive care unit discharge in clinics that track the respiratory phenotype. The data presented in this issue of Thorax is compelling evidence for long-term follow-up with a respiratory specialist. Intervening and monitoring during childhood when rapid lung growth is occurring may alter the long term pulmonary trajectory, potentially preventing development of COPD.

Contributors The authors contributed equally in the preparation of this manuscript.

Competing interests None declared.

Provenance and peer review Commissioned; externally peer reviewed.

Additional material is published online only. To view please visit the journal online (http://dx.doi.org/10. 1136/thoraxjnl-2016-209291)

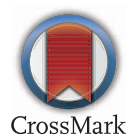

To cite Montgomery GS, Davis SD. Thorax 2017;72:680-681.

Published Online First 7 April 2017

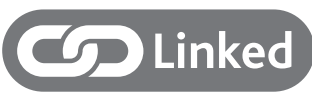

http://dx.doi.org/10.1136/thoraxinl-2016-208985

http://dx.doi.org/10.1136/thoraxjnl-2016-208524

Thorax 2017;72:680-681.

doi:10.1136/thoraxjnl-2016-209291

\section{REFERENCES}

1 Northway WH Jr, Rosan RC, Porter DY. Pulmonary disease following respirator therapy of hyaline-membrane disease. Bronchopulmonary dysplasia. N Engl J Med 1967;276:357-68.

2 Simpson SJ, Logie KM, O'Dea CA, et al. Altered lung structure and function in mid-childhood survivors of very preterm birth. Thorax 2017;72:702-11.

3 Doyle L, Adams A-M, Robertson C, et al. Increasing aimay obstruction from 8 to 18 years in extremely preterm/low birthweight survivors born in the surfactant era. Thorax 2017:72:712-9.

4 Gough $A$, Linden $M$, Spence $D$, et al. Impaired lung function and health status in adult survivors of bronchopulmonary dysplasia. Eur Respir J 2014:43:808-16.

5 Vom Hove M, Prenzel F, Uhlig HH, et al. Pulmonary outcome in former preterm, very low birth weight children with bronchopulmonary dysplasia: a case-control follow-up at school age. J Pediatr 2014;164:40-45.e4.

6 Poindexter BB, Feng R, Schmidt B, et al. Comparisons and limitations of current definitions of bronchopulmonary dysplasia for the prematurity and respiratory outcomes program. Ann Am Thorac Soc 2015;12:1822-30

7 Jobe AH, Bancalari E. Bronchopulmonary dysplasia. Am J Respir Crit Care Med 2001;163:1723-9.

8 Quanjer PH, Stanojevic S, Cole TJ, et al. Multi-ethnic reference values for spirometry for the 3-95-yr age range: the global lung function 2012 equations. Eur Respir J 2012:40:1324-43.

9 Hacking DF, Gibson AM, Robertson C, et al. Respiratory function at age 8-9 after extremely low birthweight or preterm birth in Victoria in 1997. Pediatr Pulmonol 2013:48:449-55.

10 Subbarao P, Milla C, Aurora P, et al. Multiple-breath washout as a lung function test in cystic fibrosis. A cystic fibrosis foundation workshop report. Ann Am Thorac Soc 2015;12:932-9.

11 Altes TA, Mata J, de Lange EE, et al. Assessment of lung development using hyperpolarized helium-3 diffusion MR imaging. J Magn Reson Imaging 2006;24:1277-83

12 Narayanan M, Beardsmore CS, Owers-Bradley J, et al. Catch-up alveolarization in ex-preterm children: evidence from (3)He magnetic resonance. Am J Respir Crit Care Med 2013;187:1104-9.

13 Smith JR, Emerson SR, Kurti SP, et al. Lung volume and expiratory flow rates from pre- to post-puberty. Eur J Appl Physiol 2015;115:1645-52.

14 Vilozni D, Lavie M, Sarouk I, et al. Progressive flow-to-volume dysanapsis in cystic fibrosis: a predictor for lung transplantation? Am J Respir Crit Care Med 2012;186:82-7.

15 Coalson JJ. Pathology of bronchopulmonary dysplasia. Semin Perinatol 2006;30:179-84.

16 Mourani PM, Sontag MK, Younoszai A, et al. Early pulmonary vascular disease in preterm infants at risk for bronchopulmonary dysplasia. Am J Respir Crit Care Med 2015;191:87-95.

17 Ahlfeld SK, Davis SD, Kelley KJ, et al. Early elevation of plasma periostin is associated with chronic ventilator-dependent bronchopulmonary dysplasia. Am J Respir Crit Care Med 2016;194:1430-3.

18 McEvoy CT, Jain L, Schmidt B, et al. Bronchopulmonary dysplasia: NHLBI Workshop on the Primary Prevention of Chronic Lung Diseases. Ann Am Thorac Soc 2014:11(Suppl 3):S146-53. 